\title{
Corrigendum: Impaired cross-talk between mesolimbic food reward processing and metabolic signaling predicts body mass index
}

\section{Joe J. Simon ${ }^{1}$, Mandy Skunde ${ }^{1}$, Maria Hamze Sinno ${ }^{1}$, Timo Brockmeyer ${ }^{1}$, Sabine C. Herpertz ${ }^{2}$, Martin Bendszus ${ }^{3}$, Wolfgang Herzog ${ }^{1}$ and Hans-Christoph Friederich ${ }^{1}$}

${ }^{\prime}$ Department of General Internal Medicine and Psychosomatics, Centre for Psychosocial Medicine, University Hospital Heidelberg, Heidelberg, Germany

${ }^{2}$ Department of General Adult Psychiatry, Centre for Psychosocial Medicine, University Hospital Heidelberg, Heidelberg, Germany

${ }^{3}$ Department of Diagnostic and Interventional Radiology, University Hospital Heidelberg, Heidelberg, Germany

${ }^{*}$ Correspondence: joe.simon@med.uni-heidelberg.de

\section{Edited by:}

George W. Huntley, Icahn School of Medicine at Mount Sinai, USA

Reviewed by:

Charles Mobbs, Mount Sinai School of Medicine, USA

Keywords: food reward, obesity, ventral striatum, fMRI, leptin, insulin resistance

\section{A corrigendum on}

Impaired cross-talk between mesolimbic food reward processing and metabolic signaling predicts body mass index by Simon, J. J., Skunde, M., Hamze Sinno, M., Brockmeyer, T., Herpertz, S. C., Bendszus, M., et al. (2014). Front. Behav. Neurosci. 8:359. doi: 10.3389/fnbeh.2014. 00359

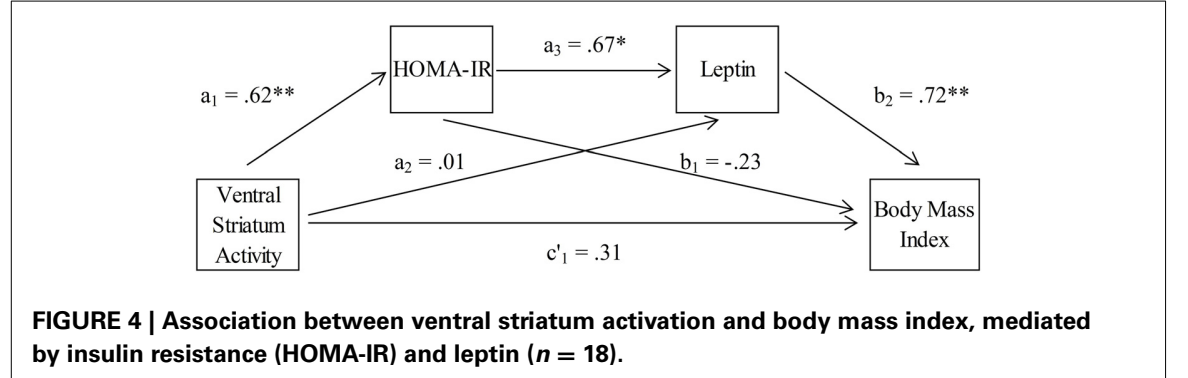

FIGURE 4 | Association between ventral striatum activation and body mass index, mediated by insulin resistance (HOMA-IR) and leptin $(n=18)$.
We have found a small error in Figure 4 in our manuscript. Inadvertently, we presented the beta value for the total effect instead of the beta value for the direct effect there. As also written in the text and in Table 3, under the arrow that connects "Ventral Striatum Activity" with "Body Mass Index" it must read c' $1=0.31$ (without asterisks). Please find attached the amended Figure.

Conflict of Interest Statement: The authors declare that the research was conducted in the absence of any commercial or financial relationships that could be construed as a potential conflict of interest.

Received: 20 November 2014; accepted: 26 November 2014; published online: 12 December 2014.

Citation: Simon JJ, Skunde M, Hamze Sinno M, Brockmeyer T, Herpertz SC, Bendszus M, Herzog W and Friederich H-C (2014) Corrigendum: Impaired crosstalk between mesolimbic food reward processing and metabolic signaling predicts body mass index. Front. Behav. Neurosci. 8:433. doi: 10.3389/fnbeh.2014.00433 This article was submitted to the journal Frontiers in Behavioral Neuroscience.

Copyright (C) 2014 Simon, Skunde, Hamze Sinno, Brockmeyer, Herpertz, Bendszus, Herzog and Friederich. This is an open-access article distributed under the terms of the Creative Commons Attribution License (CC BY). The use, distribution or reproduction in other forums is permitted, provided the original author(s) or licensor are credited and that the original publication in this journal is cited, in accordance with accepted academic practice. No use, distribution or reproduction is permitted which does not comply with these terms. 